\title{
Schisandrin B inhibits cell proliferation and induces apoptosis in human cholangiocarcinoma cells
}

\author{
XIAOHUI YANG ${ }^{1}$, SHUAI WANG $^{1}$, YUNCHUAN MU $^{1}$ and YIXIONG ZHENG ${ }^{2}$ \\ ${ }^{1}$ The Fourth Affiliated Hospital, Zhejiang University School of Medicine, Yiwu, Zhejiang 322000; \\ ${ }^{2}$ The Second Affiliated Hospital, Zhejiang University School of Medicine, Hangzhou, Zhejiang 310009, P.R. China
}

Received February 22, 2016; Accepted April 1, 2016

DOI: $10.3892 /$ or.2016.4992

\begin{abstract}
Cholangiocarcinoma (CCA) is the second most common hepatic cancer with high resistance to current chemotherapies and extremely poor prognosis. The present study aimed to examine the effects of schisandrin B (Sch B) on CCA cells both in vitro and in vivo and to examine its underlying mechanism. We found that Sch B inhibited the viability and proliferation of CCA cells in a dose- and time-dependent manner as assessed by MTT and colony formation assays. The flow cytometric assay revealed G0/G1 phase arrest in the Sch B-treated HCCC-9810 and RBE cells. In addition, Sch B induced intrahepatic cholangiocarcinoma apoptosis as shown by the results of Annexin V/PI double staining. Rhodamine 123 staining revealed that Sch B decreased the mitochondrial membrane potential $(\Delta \Psi \mathrm{m})$ in a dosedependent manner. Mechanistically, western blot analysis indicated that Sch B induced apoptosis by upregulating Bax, cleaved caspase-3, cleaved caspase- 9 and cleaved PARP, and by downregulating cyclin D1, Bcl-2 and CDK-4. Moreover, Sch B significantly inhibited HCCC-9810 xenograft growth in athymic nude mice. In summary, these findings suggest that Sch B exhibited potent antitumor activities via the induction of CCA apoptosis and that Sch B may be a promising drug for the treatment of CCA.
\end{abstract}

\section{Introduction}

Cholangiocarcinoma (CCA) is a highly malignant adenocarcinoma that originates in the extrahepatic and liver bile ducts, which terminate at the ampulla of Vater (1). CCA is generally classified into 3 forms: intrahepatic cholangiocarcinoma (ICC), hilar cholangiocarcinoma and

Correspondence to: Professor Yixiong Zheng, The Second Affiliated Hospital, Zhejiang University School of Medicine, Hangzhou, Zhejiang 310009, P.R. China

E-mail: zyx_xxn1@hotmail.com

Key words: schisandrin B, cholangiocarcinoma, proliferation, apoptosis, cell cycle extrahepatic cholangiocarcinoma (ECC) (2). Although CCA is a relatively rare neoplasm with an annual incidence rate of 1-2 cases/100,000 in the Western world, the overall incidence and mortality rates of this neoplasm appear to be rising worldwide over the past several decades $(3,4)$. Due to its late clinical presentation and the lack of effective non-surgical therapeutic modalities, the disease is difficult to diagnose and is frequently fatal (5). Over the past 30 years, the overall 5-year survival rate for patients with CCA, including those who have undergone resection, is less than $10 \%$ (6). Moreover, high drug resistance usually lowers the efficacy of chemotherapy drugs (7). Therefore, novel effective strategies and drugs are urgently needed to improve outcomes for patients with CCA.

For centuries, schisandrin B (Sch B; Fig. 1) has been a major traditional Chinese medicine. Sch B is extracted from the fruit of Schisandra chinensis Baill., and has been used to treat several human diseases, including hepatitis and myocardial disorders (8). In addition, more studies have increasingly shown that Sch B possesses antitumor activity in various types of human cancers, including glioma, gastric and breast cancer, and hepatoma (9-12). Previous studies have shown that Sch B attenuates cancer invasion and metastasis with very low toxicity (13), and it inactivates ATR when DNA damage occurs (14). However, to the best of our knowledge, the effects of Sch B on CCA cells and the underlying mechanisms of these effects have not been previously reported. In the present study, we investigated the anticancer effects of Sch B on human CCA cell lines (HCCC-9810 and RBE) and the possible molecular mechanisms underlying these actions, which provided experimental evidence for the potential application of Sch B as a new natural antitumor medicine for CCA.

\section{Materials and methods}

Cell lines and culture. The human CCA HCCC-9810 and RBE cell lines were purchased from the Shanghai Institute of Cell Biology, Chinese Academy of Sciences (CAS; Shanghai, China). All cells were grown in RPMI-1640 medium supplemented with $10 \%$ fetal bovine serum (FBS) (both from Gibco, Grand Island, NY, USA), $100 \mu \mathrm{g} / \mathrm{ml}$ streptomycin and $100 \mathrm{U} / \mathrm{ml}$ penicillin (HyClone, Logan, UT, USA). The cells were then stored in a $5 \% \mathrm{CO}_{2}$ atmosphere at $37^{\circ} \mathrm{C}$. After reaching $80 \%$ confluency, the cells were digested with $0.25 \%$ pancreatinethylene diamine tetraacetic acid diluted in a ratio of 1:3. 


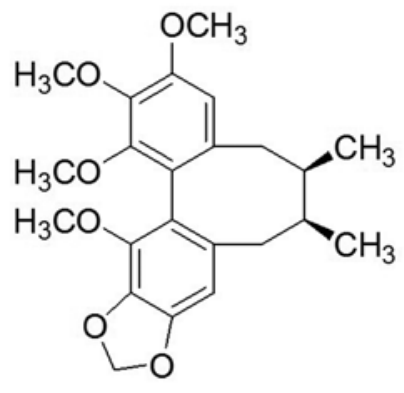

Figure 1. Chemical structure of schisandrin B.

Drugs and antibodies. Sch B and Rhodamine 123 (Rho 123) were purchased from Sigma-Aldrich (St. Louis, MO, USA). Sch B was dissolved in dimethyl sulfoxide (DMSO; Sigma-Aldrich) to create a $100 \mathrm{mM}$ stock solution. The stock solution was further diluted with culture media to acquire the desired concentrations. The control groups were treated with equal volumes of DMSO. Cell Counting Kit-8 (CCK-8) was purchased from Dojindo Laboratories (Tokyo, Japan). The Annexin V/PI apoptosis kit was obtained from BD Biosciences (San Diego, CA, USA). Primary antibodies against cleaved PARP, cleaved caspase-3, CDK4, Bcl-2, Bax, cleaved caspase-9 and cyclin D1, and secondary antibodies (goat anti-rabbit) were all purchased from Cell Signaling Technology (Danvers, MA, USA). $\beta$-actin was purchased from Abways Technology (Shanghai, China).

Colony formation assay. HCCC-9810 and RBE cells were suspended in RPMI-1640 medium at a final concentration of 200 cells/ml and seeded onto 6-well plates (Corning, Corning, NY, USA). Mediim containing 10\% FBS was replaced every 3 days. The cells were fixed and stained when a signal colony contained $>50$ cells. Then, colony-forming units were microscopically photographed. The results are expressed as the average of 3 independent experiments.

Cell viability assay. Cells were diluted into single cell suspensions and seeded in 96-well plates $\left(1 \times 10^{3}\right.$ cells/well) in $100 \mu 1$ culture medium. Following overnight incubation, the cells were treated with various concentrations $(0,10,20,40,80$ and $160 \mu \mathrm{mol} / \mathrm{l})$ of Sch B. At each time point (24, 48 and $72 \mathrm{~h})$, $10 \mu$ l CCK-8 solution was added to each well and incubated for $3 \mathrm{~h}$ in the incubator, and the absorbance was determined at $450 \mathrm{~nm}$ using a microplate reader (Bio-Tek, Winooski, VT, USA). The cell survival rate was calculated as the percentage of absorbance in individual Sch B-treated wells vs. untreated control wells. The results represent the average of 5 parallel samples. All experiments were repeated at least 3 times.

Cell cycle analysis. After treatment with different concentrations of Sch B for 48 h, HCCC-9810 and RBE cells were harvested, fixed in $70 \%$ ethanol and stored at $4^{\circ} \mathrm{C}$. On the day of analysis, the cells were washed and incubated in staining buffer $[10 \mathrm{mg} / \mathrm{ml} \mathrm{RNase}$ and $1 \mathrm{mg} / \mathrm{ml}$ propidium iodide (PI) (Sigma-Aldrich)] at $37^{\circ} \mathrm{C}$ in the dark for $30 \mathrm{~min}$. Next, the samples were analyzed using flow cytometry (BD Biosciences). Cell Quest acquisition software was used to calculate the percentages of cells in the G0/G1, S and G2/M phases.
Mitochondrial membrane potential $(\Delta \Psi m)$ assay. Rho 123 was used to measure the $\Delta \Psi \mathrm{m}$ according to previously reported methods with some modifications (15). Briefly, after treatment with Sch B (20,40 and $80 \mu \mathrm{mol} / \mathrm{l})$ for $48 \mathrm{~h}$, cells were harvested and incubated with medium containing Rho $123(10 \mu \mathrm{g} / \mathrm{ml})$ for $30 \mathrm{~min}$ in a $5 \% \mathrm{CO}_{2}$ atmosphere at $37^{\circ} \mathrm{C}$ in the dark. The samples were then analyzed by flow cytometry. In all cases, the samples were gated to exclude cellular debris. Each assay was carried out in triplicate, and the results are expressed as the mean $\pm \mathrm{SD}$.

Cell apoptosis assay. Apoptosis was detected using the FITC Annexin $\mathrm{V}$ apoptosis detection kit (BD Biosciences) according to the manufacturer's instructions. Briefly, cells were treated with Sch B $(0,20,40$ and $80 \mu \mathrm{mol} / \mathrm{l})$ for $48 \mathrm{~h}$. The cells were then washed and resuspended in $1 \mathrm{X}$ binding buffer at a density of $1 \times 10^{6}$ cells $/ \mathrm{ml}$. Then, the cells were incubated with $5 \mu \mathrm{l}$ Annexin V-FITC and $5 \mu \mathrm{l} \mathrm{PI}(100 \mu \mathrm{g} / \mathrm{ml})$ for $15 \mathrm{~min}$ in the dark at room temperature. The stained cells were diluted with $400 \mu \mathrm{l}$ binding buffer and immediately detected by flow cytometry (BD Biosciences). Each sample was assayed in duplicate, and the experiment was repeated 3 times.

Western blot analysis. HCCC-9810 and RBE cells were treated with Sch B $(0,20,40$ and $80 \mu \mathrm{mol} / \mathrm{l})$ for $48 \mathrm{~h}$. The cells were harvested and lysed in RIPA buffer (Beyotime Institute of Biotechnology, Beijing, China) supplemented with protease inhibitor (Roche Applied Science, Indianapolis, IN, USA) at $4^{\circ} \mathrm{C}$ for $15 \mathrm{~min}$. Then, cells were centrifuged in a microcentrifuge at $12,000 \mathrm{x}$ g for $15 \mathrm{~min}$ at $4^{\circ} \mathrm{C}$ to collect the supernatant. The protein concentration was measured using the bicinchoninic acid (BCA) assay kit (Beyotime). A total of $30 \mu \mathrm{g}$ of protein/lane was subjected to SDS-polyacrylamide gel electrophoresis (PAGE) after boiling for $5 \mathrm{~min}$ in 1X SDS sample buffer, and then electrophoretically transferred to polyvinylidene difluoride membranes (Millipore, Bedford, MA, USA). After blocking with 5\% skim milk for $1-2 \mathrm{~h}$ at room temperature, the membranes were then incubated with the indicated primary antibodies against Bcl-2, Bax, cleaved caspase-9, cleaved PARP, cyclin D1, cleaved caspase-3, CDK4 and $\beta$-actin $(1: 1,000)$ at $4^{\circ} \mathrm{C}$ overnight. After washing with Tris-buffered saline and Tween-20 (TBST) buffer for $3 \times 5 \mathrm{~min}$, the blots were then re-probed with the secondary antibodies conjugated to horseradish peroxidase for $1 \mathrm{~h}$ at room temperature. The protein bands were detected using enhanced chemiluminescence and visualized using a Gel Doc 2000 (Bio-Rad, Hercules, CA, USA).

In vivo tumor xenograft study. Male athymic nude mice (5-6 weeks old) were purchased from Shanghai SLAC Laboratory Animal Co., Ltd. (Shanghai, China). All animal experiments were performed in strict accordance with the Institutional Animal Care and Use Committee-approved protocol. The mice were housed in a specific pathogen-free environment. HCCC-9810 cells in log-phase growth $\left(2.5 \times 10^{6}\right)$ suspended in $100 \mu \mathrm{l}$ phosphate-buffered saline (PBS) were subcutaneously inoculated into the right flank of the nude mice. Sch B treatment was started 7 days after inoculation of the cells. The control group $(n=8)$ was administered PBS intraperitoneally, whereas the other two treatment groups 
A
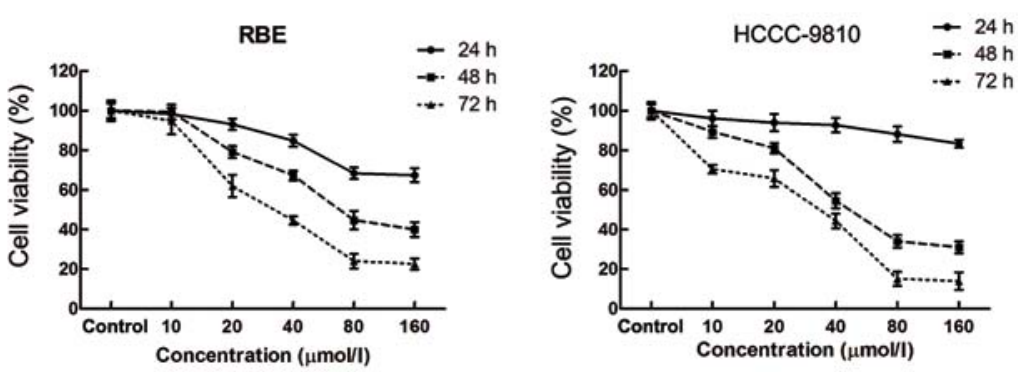

B

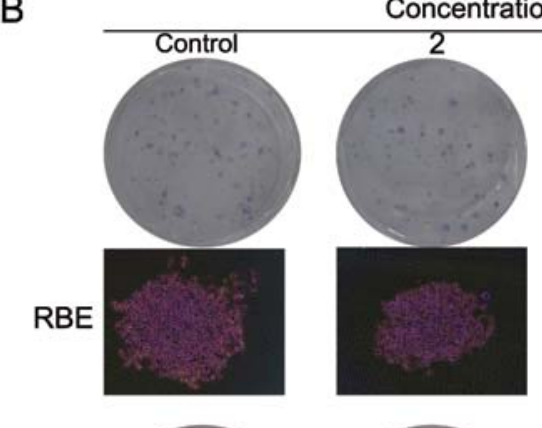

Concentration $(\mu \mathrm{mol} / \mathrm{l})$
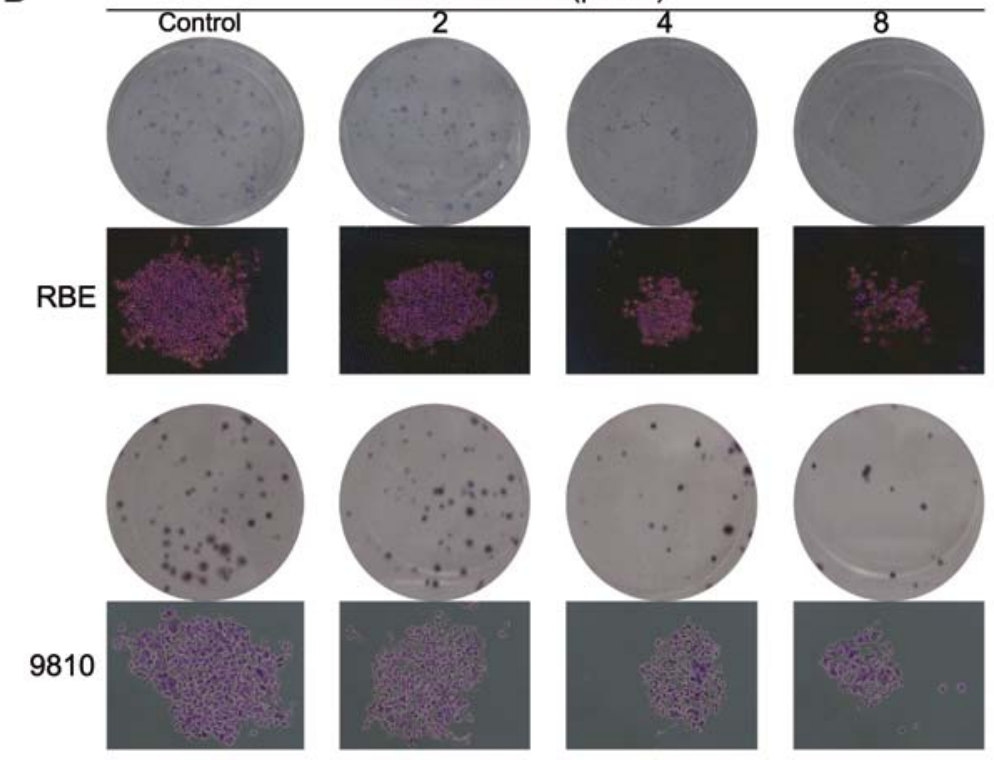

C
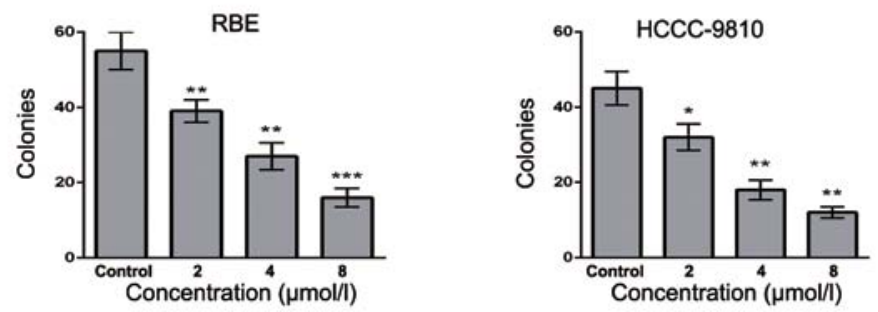

Figure 2. Schisandrin B inhibits the proliferation of CCA cells. (A) RBE and HCCC-9810 cells were treated with various concentrations of Sch B for 24, 48 and $72 \mathrm{~h}$. Cell viability was examined using the CCK-8 assay. (B and C) RBE and HCCC-9810 cells were treated with Sch B (2, 4 and $8 \mu \mathrm{mol} / \mathrm{l})$ for $48 \mathrm{~h}$. Then, the medium was replaced with fresh medium, and the cells were cultured for another 14 days. (B) The colonies were then stained by Giemsa. (C) The numbers of colonies of RBE and HCCC-9810 cells were counted. The data are expressed as the mean \pm SD of 3 replicate experiments; ${ }^{*} \mathrm{P}<0.05,{ }^{* *} \mathrm{P}<0.01,{ }^{* * *} \mathrm{P}<0.001$ vs. the control group.

$(\mathrm{n}=8)$ were administered Sch B (20 and $80 \mathrm{mg} / \mathrm{kg})$ intraperitoneally every 2 days for up to 30 days. On day 30, all mice were sacrificed, and the tumors were removed and weighed.

Statistical analysis. All of the experiments were independently repeated 3 times. Numerical data are presented as the mean \pm standard deviation. Statistically significant differences between samples were determined using the Student's t-test. $\mathrm{P}<0.05$ was considered to indicate a statistically significant result.

\section{Results}

Sch B inhibits the proliferation and decreases the cell viability of CCA cells in a dose-dependent manner. To investigate the effect of Sch B on human CCA cells, HCCC-9810 and RBE cells were treated with Sch B at concentrations of $0-160 \mu \mathrm{M}$ for 24,48 and $72 \mathrm{~h}$ followed by detection of cell viability. The results of the CCK-8 assay showed that Sch B decreased the cell viability of the HCCC-9810 and RBE cells in a dose- and time-dependent manner (Fig. 2A). The $\mathrm{IC}_{50}$ values (the drug concentration that inhibited $50 \%$ of the cells) of Sch B in the HCCC-9810 and RBE cells at $48 \mathrm{~h}$ were $40 \pm 1.6$ and $70 \pm 2.6 \mu \mathrm{mol} / 1$, respectively. As shown in Fig. $2 \mathrm{~B}$ and $\mathrm{C}$, the numbers of colonies of RBE and HCC-9810 cells were significantly reduced in a concentration-dependent manner after treatment with Sch B. The individual colony size in Sch B-treated group was also smaller than that of control group as shown in Fig. 2B. These results suggested that Sch B inhibited the proliferation of CCA cells.

Sch B induces G0/G1 phase arrest in HCCC-9810 and RBE cells. To determine whether Sch B-induced cytotoxicity was caused by cell cycle arrest, we performed cell cycle distribu- 
A

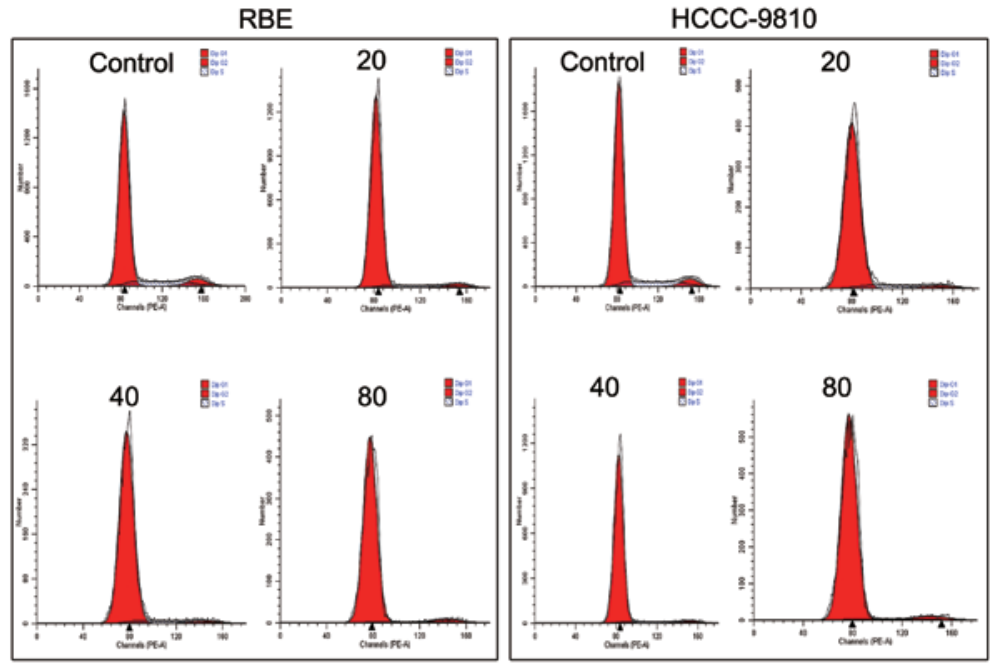

B
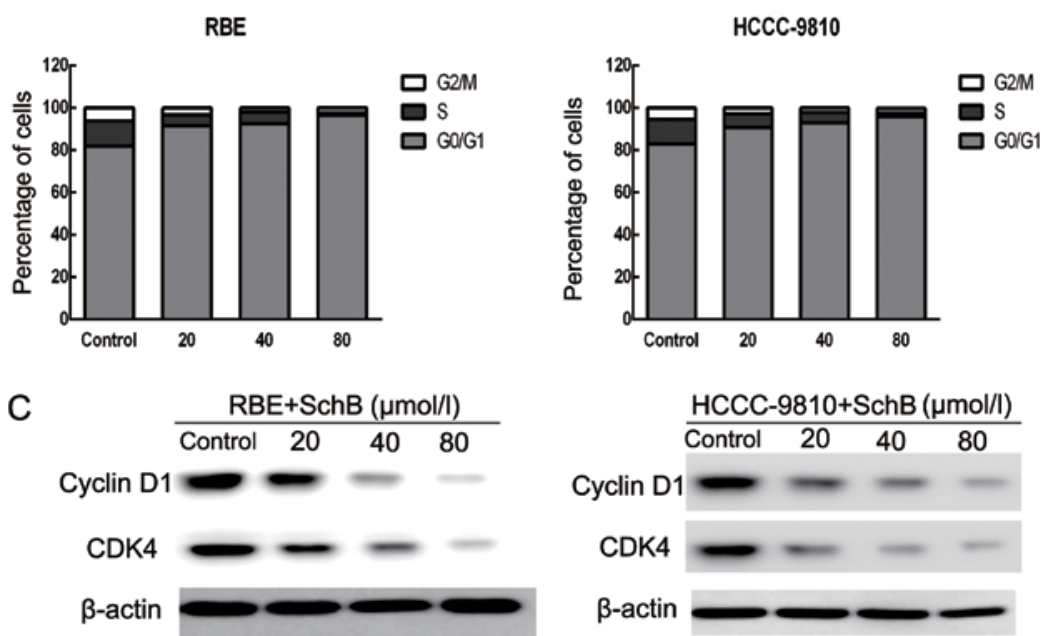

Figure 3. Schisandrin B induces cell cycle arrest in CCA cells. (A) The cell cycle distribution of RBE and HCCC-9810 cells was evaluated by flow cytometry after the addition of different concentrations of Sch B (0,20,40 and $80 \mu \mathrm{mol} / \mathrm{l})$ for $48 \mathrm{~h}$. (B) Data are calculated and expressed as the mean \pm SD (n=3). (C) Expression levels of cyclin D1 and CDK4 in RBE and HCCC-9810 cells were measured by western blot analysis with $\beta$-actin as a loading control.

tion analysis in the HCCC-9810 and RBE cells after exposure to Sch B. As shown in Fig. 3A and B, Sch B induced G0/ G1 phase arrest (from 82.94 to $95.75 \%$ for HCCC-9810 cells and from 81.9 to $96.62 \%$ for RBE cells) with a slight $S$ phase decrease compared with that of the control cells.

Next, we assessed the protein expression of the G0/G1 phase regulatory genes after Sch B treatment. As shown in Fig. 3C, the expression levels of cyclin D1 and CDK4 were reduced in a dose-dependent manner after treatment with Sch B. These results illustrated that Sch B blocked the cell cycle to inhibit CCA cell proliferation.

Sch B induces apoptosis in human CCA cells. To further elucidate whether the inhibition of cell growth was caused by apoptosis, we performed Annexin V/PI dual staining followed by flow cytometric analysis after stimulation with various doses of Sch B. The translocation of phosphatidylserine (PS) from the inner leaflet to the outer leaflet of the plasma membrane is a marker of apoptosis. Apoptotic and necrotic cells can be identified via fluorophore-labeled Annexin V, which has a high affinity for PS. In addition, PI nucleic acid dye gains entry into late apoptotic and necrotic cells, but not into early apoptotic and living cells. Therefore, various cell populations can be easily distinguished using Annexin V/PI staining. As assessed by flow cytometry and as shown in Fig. $4 \mathrm{~A}$ and B, the number of surviving cells was decreased (from 90.1 to $33.2 \%$ for HCCC-9810 cells and from 89.4 to $28.9 \%$ for RBE cells) and the number of early apoptotic cells was markedly increased (from 5.9 to $61.2 \%$ for HCCC-9810 cells and from 4.8 to $65.4 \%$ for RBE cells) in a dose-dependent manner after Sch B treatment compared with the control group. These results are consistent with the cell viability results as determined by the CCK-8 assay, suggesting that the apoptotic cell death pathway may play a key role in the antiproliferative effect of Sch B on HCCC-9810 and RBE cells.

Sch $B$ decreases $\triangle \Psi m$ in CCA cells. To examine whether mitochondrial membrane integrity is disrupted by Sch B treatment, cells were stained with Rho 123, and staining was detected by flow cytometry. The loss of the $\Delta \Psi \mathrm{m}$ was reflected by a decrease in the intensity of Rho 123 fluorescent staining. Compared with the control cells, Sch B treatment markedly 

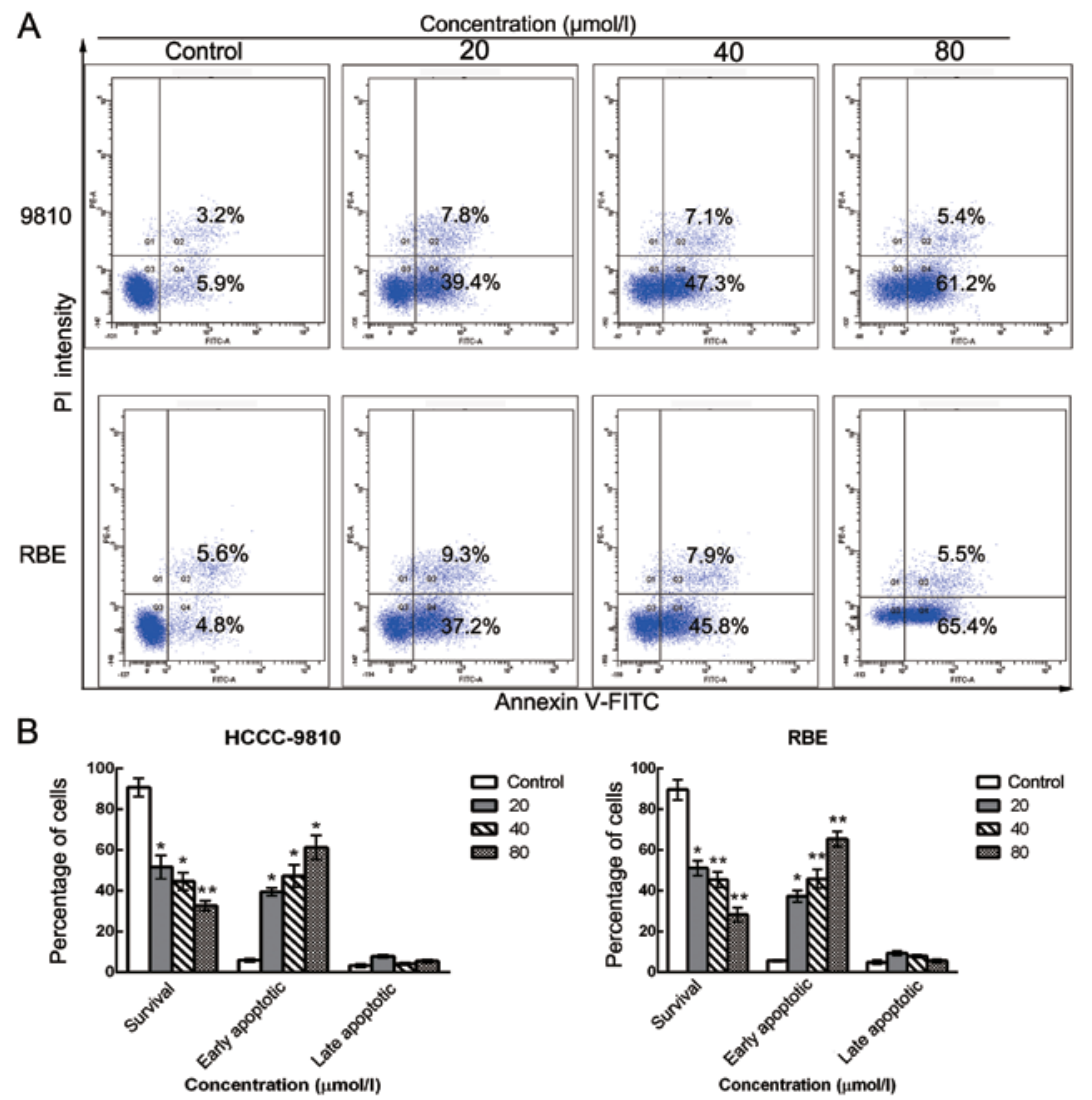

Figure 4. Schisandrin B induces apoptosis in CCA cells. HCCC-9810 and RBE cells were treated with Sch B (0, 20, 40 and $80 \mu$ mol/l) for 48 h. (A) Flow cytometric analysis of apoptosis quantification by dual Annexin V-FITC and propidium iodide (PI) staining in untreated cells or Sch B-treated cells. (B) Percentages of surviving and early and late apoptotic cells are presented as the means $\pm \mathrm{SD}(\mathrm{n}=3)$. Significant differences from control experiments; ${ }^{*} \mathrm{P}<0.01,{ }^{* *} \mathrm{P}<0.001$.
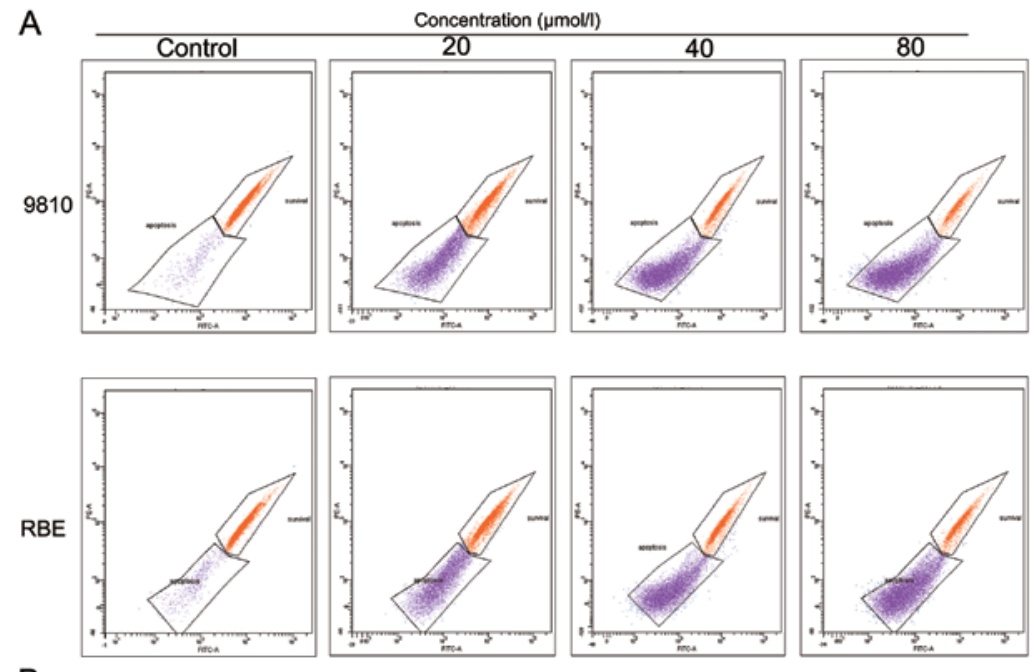

B

HCCC-9810

RBE
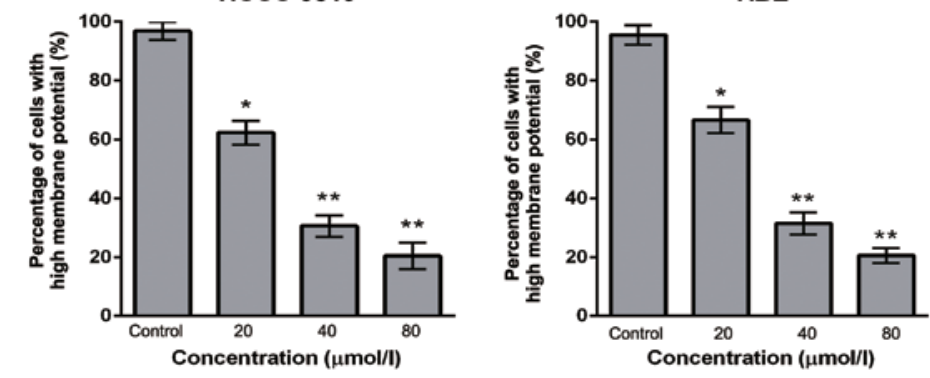

Figure 5. Schisandrin B disrupts mitochondrial integrity in CCA cells. HCCC-9810 and RBE cells were exposed to Sch B $(0,25,50$ and $100 \mu \mathrm{mol} / \mathrm{l})$ for $48 \mathrm{~h}$. (A) Rhodamine 123 staining was analyzed by flow cytometric analysis. (B) The corresponding histogram shows the percentages of cells with high $\Delta \Psi \mathrm{m}$ (survival). The results shown are representative data from 3 independent experiments; ${ }^{*} \mathrm{P}<0.05,{ }^{* * *} \mathrm{P}<0.01$ vs. the control group. 

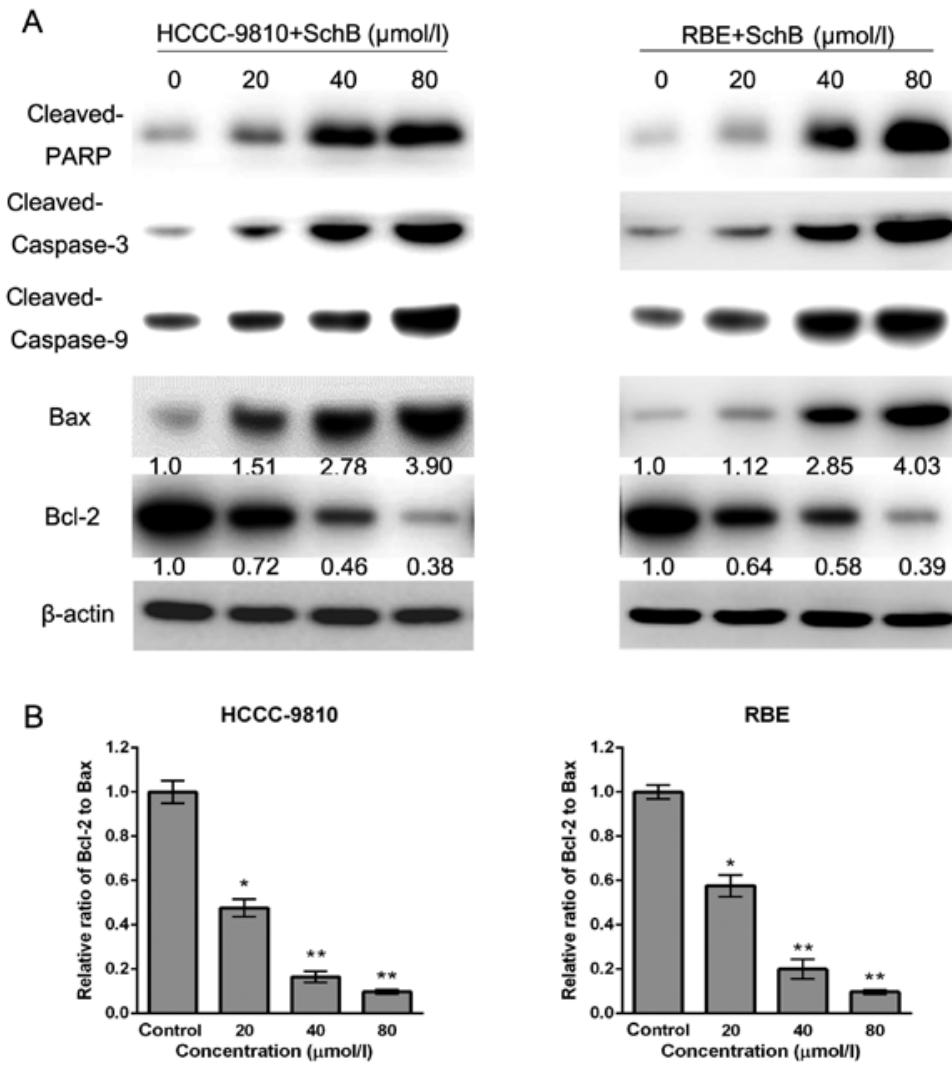

Figure 6. Schisandrin B regulates the expression of apoptosis-related proteins in CCA cells. HCCC-9810 and RBE cells were treated with Sch B for $48 \mathrm{~h}$, and cell lysates were prepared. (A) The expression levels of cleaved PARP, cleaved caspase-3, cleaved caspase-9, Bax and Bcl-2 were detected by western blotting. $\beta$-actin served as a loading control. (B) The band density was determined, and the ratio of Bcl-2 to Bax was calculated. The results are expressed as the mean \pm SD compared with the control (designated as 1.00 ); ${ }^{*} \mathrm{P}<0.05,{ }^{* *} \mathrm{P}<0.01$ compared with the control group.
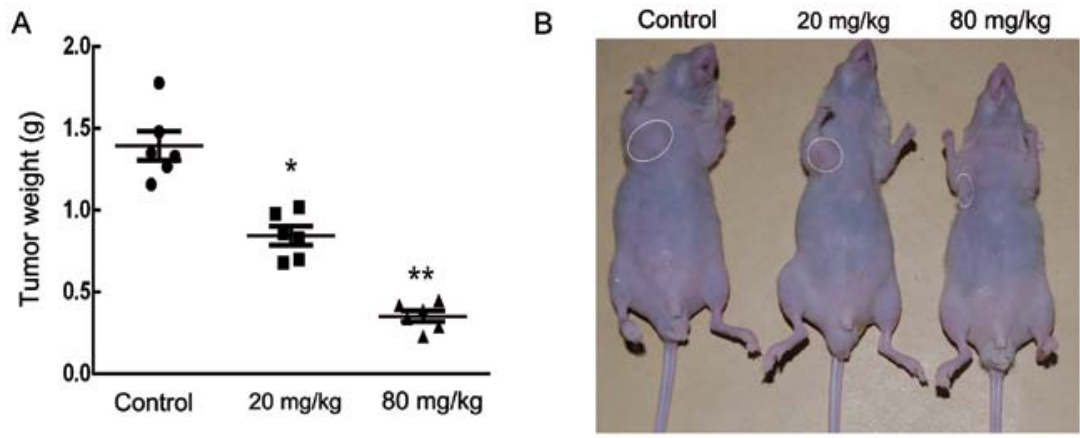

Figure 7. Schisandrin B suppressed the growth of HCCC-9810 cells in vivo. HCCC-9810 cells were subcutaneously injected into the right flank of nude mice. Then, vehicle (PBS) or Sch B (20 and $80 \mathrm{mg} / \mathrm{kg}$ ) were intraperitoneally injected every 2 days for up to 30 days. (A) At the end of the experiment, mice were sacrificed, and tumors were resected and weighed in each group. (B) A representative mouse from each group $(\mathrm{n}=6)$ is photographed; ${ }^{*} \mathrm{P}<0.05,{ }^{* *} \mathrm{P}<0.01$, ${ }^{* * *} \mathrm{P}<0.001$ vs. the control group.

decreased Rho 123-positive cells (from 96.9 to $18.2 \%$ for HCCC-9810 cells and from 95.6 to $20.5 \%$ for RBE cells) in a dose-dependent manner (Fig. 5A and B). These findings suggest that Sch B promotes the apoptosis of CCA cells through a mitochondrial-dependent apoptotic pathway.

Sch B induces apoptosis via the regulation of caspase- 3 and Bcl-2 family members in CCA cells. To investigate the underlying molecular mechanisms responsible for Sch B-induced apoptosis of HCCC-9810 and RBE cells, we assessed the expression of apoptosis-related factors (cleaved PARP, Bax, Bcl-2, cleaved caspase-3 and cleaved caspase-9) after Sch B treatment by western blot analysis. As shown in Fig. 6A, increased expression of cleaved PARP, Bax, cleaved caspase- 9 and cleaved caspase- 3 , and decreased expression of Bcl-2 was observed after Sch B treatment, which was consistent with apoptosis induced by Sch B. Furthermore, compared with the control group, the Bcl-2 (anti-apoptotic) to Bax (pro-apoptotic) ratio was significantly decreased (Fig. 6B). Our results suggest that Sch B promotes apoptosis through the regulation and activation of apoptosis-related proteins in CCA cells.

Sch B inhibits tumor growth in vivo. The anticancer effect of Sch B on tumor growth in vivo was further analyzed by intra- 
peritoneally injecting vehicle (PBS) or Sch B (20 and $80 \mathrm{mg} / \mathrm{kg}$ ) into nude mice bearing subcutaneous HCCC-9810 tumor xenografts every 2 days for up to 30 days. As shown in Fig. 7A and B, there was a marked dose-dependent reduction in tumor weight in mice treated with oridonin compared with the control mice.

\section{Discussion}

Previous studies have demonstrated that Sch B promoted apoptosis in a wide range of human cancers (9-12). However, little is known concerning the antitumor activity of Sch B on cholangiocarcinoma (CCA) cells and its underlying mechanisms. In the present study, for the first time, we examined the inhibitory effect and mechanism of Sch B on CCA cells. We showed that Sch B dose-dependently decreased cell viability and induced cell cycle arrest and apoptosis in CCA cells. Our in vivo study showed that Sch B strongly suppressed tumor growth. Thus, Sch B may be a promising drug for CCA prevention and treatment.

To examine the mechanism of Sch B-induced inhibition of cell survival, we performed the cell cycle distribution experiment in the presence of Sch B and found that it induced G0/G1 phase arrest. Further study showed that Sch B treatment resulted in a downregulation of the expression of cyclin D1 and CDK4 in both HCCC-9810 and RBE cells (Fig. 3C). It is well known that the cell cycle is a tightly regulated process consisting of 4 distinct phases: G0/G1, S, G2 and M. Activation of each phase is dependent on the regulation of various cyclins and cyclin-dependent kinases (Cdks) $(16,17)$. The complex of cyclin D1 and CDK4 is the main driver of the transition of cells from $\mathrm{G} 0 / \mathrm{G} 1$ to $\mathrm{S}$ phase by phosphorylating of retinoblastoma (Rb) (18-20). Hyper-phosphorylated Rb activates E2F after its dissociation from the E2F/DP1/Rb complex (21). As suggested by our cell cycle analysis data, Sch B arrested HCCC-9810 and RBE cells at the G0/G1 phase (Fig. 3A), which may be due to the downregulation of cyclin D1 and CDK4.

Apoptosis, genetically programmed cell death that plays crucial roles in cell death and survival, is considered to be one of the main contributors to cancer development. Chemical compounds that induce cancer cell apoptosis are considered promising anticancer drugs $(22,23)$. Caspases, a family of cysteine proteases, play essential roles in apoptosis. Both the death-receptor-induced extrinsic pathway and the mitochondriaapoptosome-mediated intrinsic pathway ultimately activate caspases $(24,25)$. Among them, caspase-3, which is activated by caspase- 8 or -9 , is one of the most important executioner caspases (26). Caspase-3 cleaves several cellular proteins, including the PARP protein, resulting in morphological changes and DNA fragmentation that eventually lead to apoptosis (27). In the present study, we observed the activation of caspase- 9 and -3 and the cleavage of PARP following Sch B treatment in HCCC9810 and RBE cells, indicating that the mitochondrial pathway was involved in Sch B-induced apoptosis.

Bcl-2 family proteins, including Bax, Bad, Bid, Bcl-2 and Bcl-xL, play essential roles in the mitochondriamediated apoptosis pathway by regulating the release of cytochrome $c$ (28). The pro-apoptotic members Bax and Bad induce the release of cytochrome $c$ from the mitochondria within cells, whereas anti-apoptotic Bcl-2 and Bcl-xL promote cell survival by preventing cytochrome $c$ release from the mitochondria $(29,30)$. A low Bcl-2 to Bax ratio can induce $\Delta \Psi \mathrm{m}$ collapse, the release of cytochrome $c$, and subsequent apoptosis (31). The present study showed that the apoptosis that occurs in response to Sch B treatment is accompanied by decreased expression of anti-apoptotic genes and increased expression of pro-apoptotic genes. Consistent with this result, an obvious decrease of $\Delta \Psi \mathrm{m}$ was observed in CCA cells treated with Sch B. Taken together, these results indicate that the mitochondrial pathway is involved in Sch B-induced apoptosis. Sch B may be a promising drug for CCA treatment. However, further studies are certainly needed to elucidate the mechanism underlying Sch B-induced apoptosis.

\section{Acknowledgements}

The present study was supported by grants from the Major Science and Technology Projects of Zhejiang Province (2014C04008-1).

\section{References}

1. de Groen PC, Gores GJ, LaRusso NF, Gunderson LL and Nagorney DM: Biliary tract cancers. N Engl J Med 341: 1368-1378, 1999.

2. Tyson GL, Ilyas JA, Duan Z, Green LK, Younes M, El-Serag HB and Davila JA: Secular trends in the incidence of cholangiocarcinoma in the USA and the impact of misclassification. Dig Dis Sci 59: 3103-3110, 2014.

3. Landis SH, Murray T, Bolden S and Wingo PA: Cancer statistics, 1998. CA Cancer J Clin 48: 6-29, 1998.

4. Patel T: Worldwide trends in mortality from biliary tract malignancies. BMC Cancer 2: 10, 2002.

5. Khan SA, Davidson BR, Goldin R, Pereira SP, Rosenberg WM, Taylor-Robinson SD, Thillainayagam AV, Thomas HC, Thursz MR and Wasan H; British Society of Gastroenterology: Guidelines for the diagnosis and treatment of cholangiocarcinoma: Consensus document. Gut 51 (Suppl 6): VI1-VI9, 2002.

6. Zhang TC, Cao EH, Li JF, Ma W and Qin JF: Induction of apoptosis and inhibition of human gastric cancer MGC-803 cell growth by arsenic trioxide. Eur J Cancer 35: 1258-1263, 1999.

7. Shaib Y and El-Serag HB: The epidemiology of cholangiocarcinoma. Semin Liver Dis 24: 115-125, 2004.

8. Liu GT: Pharmacological actions and clinical use of fructus schizandrae. Chin Med J 102: 740-749, 1989.

9. Li L, Wang T, Xu ZL, Yu Y, Chen W and Chen F: Effects of schisandrin $\mathrm{B}$ on reversing multidrug resistance in human breast cancer cells transfected with mdrl gene. Zhonghua Yi Xue Za Zhi 85: 1633-1637, 2005 (In Chinese).

10. Liu XN, Zhang CY, Jin XD, Li YZ, Zheng XZ and Li L: Inhibitory effect of schisandrin $B$ on gastric cancer cells in vitro. World J Gastroenterol 13: 6506-6511, 2007.

11. Wu YF, Cao MF, Gao YP, Chen F, Wang T, Zumbika EP and Qian KX: Down-modulation of heat shock protein 70 and up-modulation of caspase-3 during schisandrin B-induced apoptosis in human hepatoma SMMC-7721 cells. World J Gastroenterol 10: 2944-2948, 2004.

12. Li Q, Lu XH, Wang CD, Cai L, Lu JL, Wu JS, Zhuge QC, Zheng WM and Su ZP: Antiproliferative and apoptosis-inducing activity of schisandrin B against human glioma cells. Cancer Cell Int 15: 12, 2015.

13. Liu Z, Zhang B, Liu K, Ding Z and Hu X: Schisandrin B attenuates cancer invasion and metastasis via inhibiting epithelial-mesenchymal transition. PLoS One 7: e40480, 2012.

14. Nishida H, Tatewaki N, Nakajima Y, Magara T, Ko KM, Hamamori Y and Konishi T: Inhibition of ATR protein kinase activity by schisandrin B in DNA damage response. Nucleic Acids Res 37: 5678-5689, 2009.

15. Hu YP, Tan ZJ, Wu XS, Liu TY, Jiang L, Bao RF, Shu YJ, Li ML, Weng H, Ding Q, et al: Triptolide induces s phase arrest and apoptosis in gallbladder cancer cells. Molecules 19: 2612-2628, 2014. 
16. Bloom $\mathrm{J}$ and Cross FR: Multiple levels of cyclin specificity in cell-cycle control. Nat Rev Mol Cell Biol 8: 149-160, 2007.

17. Nigg EA: Cyclin-dependent protein kinases: Key regulators of the eukaryotic cell cycle. BioEssays 17: 471-480, 1995.

18. Harbour JW, Luo RX, Dei Santi A, Postigo AA and Dean DC: Cdk phosphorylation triggers sequential intramolecular interactions that progressively block Rb functions as cells move through G1. Cell 98: 859-869, 1999.

19. Ezhevsky SA, Ho A, Becker-Hapak M, Davis PK and Dowdy SF: Differential regulation of retinoblastoma tumor suppressor protein by $\mathrm{G}_{1}$ cyclin-dependent kinase complexes in vivo. Mol Cell Biol 21: 4773-4784, 2001.

20. Hinds PW, Mittnacht S, Dulic V, Arnold A, Reed SI and Weinberg RA: Regulation of retinoblastoma protein functions by ectopic expression of human cyclins. Cell 70: 993-1006, 1992.

21. Massagué J: G1 cell-cycle control and cancer. Nature 432 298-306, 2004.

22. Chinkwo KA: Sutherlandia frutescens extracts can induce apoptosis in cultured carcinoma cells. J Ethnopharmacol 98: $163-170,2005$

23. Asgar MA, Senawong G, Sripa B and Senawong T: Synergistic anticancer effects of cisplatin and histone deacetylase inhibitors (SAHA and TSA) on cholangiocarcinoma cell lines. Int J Oncol 48: 409-420, 2016.
24. Hu W and Kavanagh JJ: Anticancer therapy targeting the apoptotic pathway. Lancet Oncol 4: 721-729, 2003.

25. Reed JC: Apoptosis-regulating proteins as targets for drug discovery. Trends Mol Med 7: 314-319, 2001.

26. Zheng L, Zheng J, Wu LJ and Zhao YY: Julibroside J8-induced HeLa cell apoptosis through caspase pathway. J Asian Nat Prod Res 8: 457-465, 2006.

27. Antonsson B: Mitochondria and the Bcl-2 family proteins in apoptosis signaling pathways. Mol Cell Biochem 256-257: 141-155, 2004.

28. Pal S, Pal PB, Das J and Sil PC: Involvement of both intrinsic and extrinsic pathways in hepatoprotection of arjunolic acid against cadmium induced acute damage in vitro. Toxicology 283 : 129-139, 2011.

29. Tsujimoto Y: Bcl-2 family of proteins: Life-or-death switch in mitochondria. Biosci Rep 22: 47-58, 2002.

30. Das A, Banik NL, Patel SJ and Ray SK: Dexamethasone protected human glioblastoma U87MG cells from temozolomide induced apoptosis by maintaining Bax:Bcl-2 ratio and preventing proteolytic activities. Mol Cancer 3: 36, 2004.

31. Zhang YH, Wu YL, Tashiro S, Onodera S and Ikejima T: Reactive oxygen species contribute to oridonin-induced apoptosis and autophagy in human cervical carcinoma HeLa cells. Acta Pharmacol Sin 32: 1266-1275, 2011. 